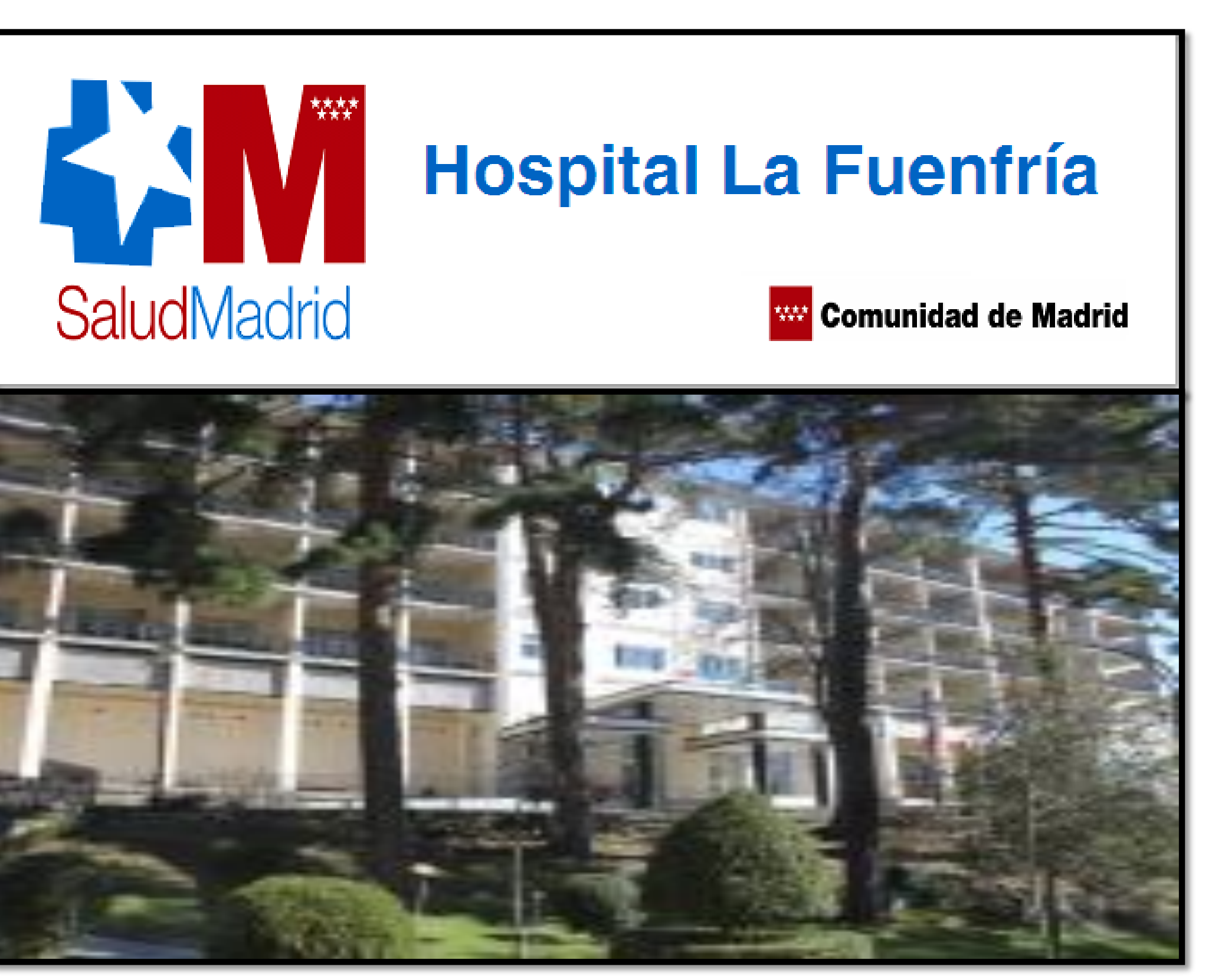

\title{
EVALUATION BY BAROPODOMETRY OF STROKE PATIENT WITH IN SUBACUTE PHASE
}

RODRIGUEZ HERNANDEZ, J (1), CANO MAÑAS, M.J (2), GÓMEZ LÓPEZ,D ${ }_{(3)}$, COLLADO VÁZQUEZ, $S_{(4)} \&$ CANO DE LA CUERDA, $\mathbf{R}_{(4)}$ MEDICAL DIRECTOR LA FUENFRíA HOSPITAL (1), PHYSICAL THERAPIST LA FUENFRÍA HOSPITAL (2), REHABILITATION LA FUENFRía HOSPITAL (3),
REHABILITATION \& PHYSICAL MEDICINE UNIVERSIDAD REY JUAN CARLOS (4)

ESOC 2019 The Voice of Stroke in Europe

$5^{\text {th }}$ European Stroke Organisation Conference 22 - 24 May 2019 | Milan, Italy

\section{INTRODUCTION}

The stroke triggers numerous deficits in the patient generating situations of partial or complete dependence. Alterations in postural control take priority in neurorehabilitation interventions in order to reduce the impact of the disease on the person and their environment.

\section{OBJECTIVE}

To determine if baropodometry can be a useful tool to demonstrate changes in postural control in patients with stroke in the subacute phase, admitted to a medium and long stay hospital

\section{MATERIAL AND METHODS}

We performed a longitudinal prospective pilot study with pre and post intervention assessment. Fourteen participants admitted to La Fuenfría Hospital were included. The experimental intervention was performed for eight weeks through a combined protocol with conventional treatment of physiotherapy and occupational therapy. The protocol included 24 sessions with commercial video games linked to the Xbox 360 game console and the Kinect ${ }^{\ominus}$ device. Each session was increased in intensity-time and motor requirements. To quantify "Postural Control" the T-plate ${ }^{\circledR}$ podometer was used, which provided information on the pressure exerted by each point of the sole, distribution and plantar symmetry by means of a static standing test.

This test records the center of pressures at a given time, offering information on the load distribution (\%) and the support surface $\left(\mathrm{cm}^{2}\right)$.
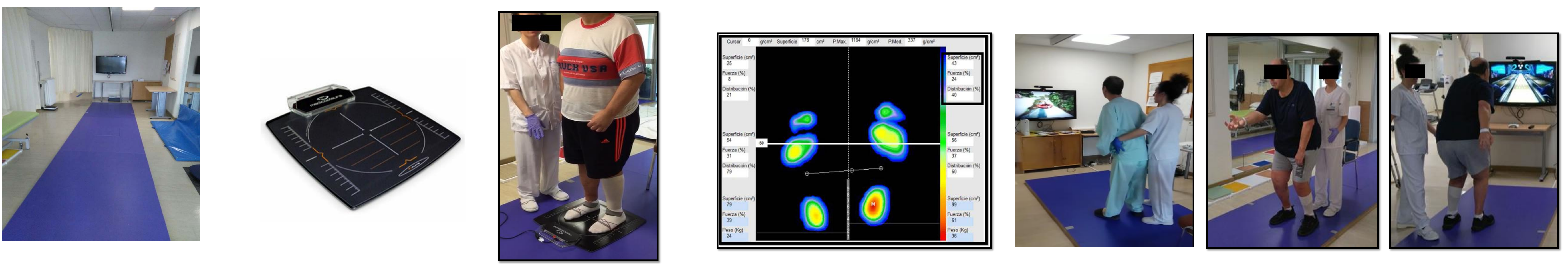

\section{RESULTS}

We found statistically significant data in baropodometry in the variables 'load distribution' and 'support surface' ( $p=0.03$ and $p$ $=0.01$, respectively). Objective changes in body alignment and support symmetry could be determined.

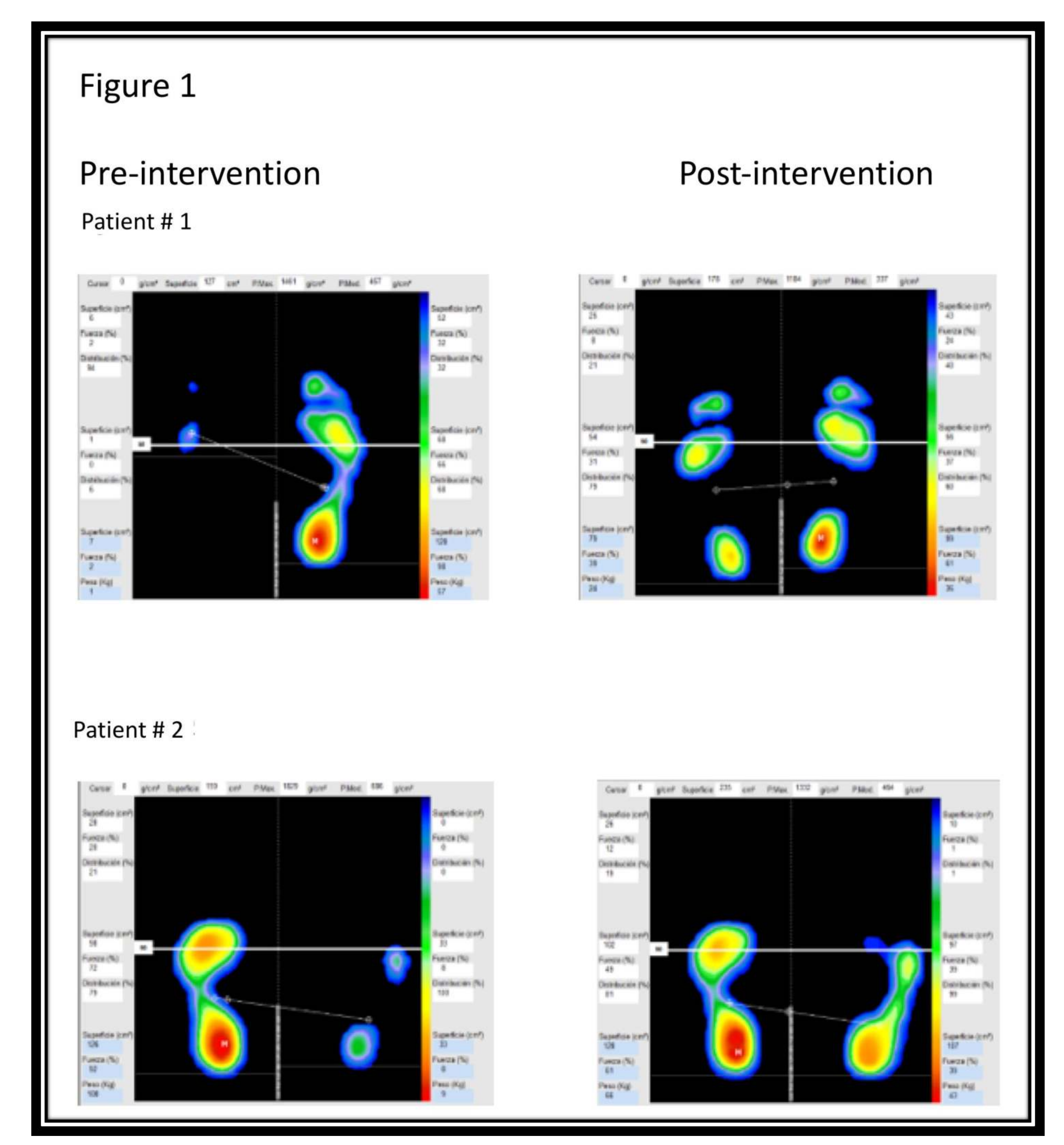

Table 1 Descriptive statistics of the variables of static baropomodetry used pre and post- intervention of the postural control of stroke patients with in sub-acute phase

\begin{tabular}{|c|c|c|c|c|c|c|c|c|c|c|c|}
\cline { 2 - 12 } & \multicolumn{4}{|c|}{ PRE- INTERVENTON } & \multicolumn{5}{c|}{ POST- INTERVENTION } & \multirow{2}{*}{$p$} \\
\cline { 2 - 12 } & $\mathrm{N}$ & Mean & SD & Min & Max & N & Mean & SD & Min & Max & \\
\hline Load distribution (\%) & 14 & 72 & 18.84 & 48 & 100 & 14 & 62,78 & 14,15 & 45 & 96 & 0,03 \\
\hline Support surface $\left(\mathrm{cm}^{2}\right)$ & 14 & 143,29 & 40.68 & 103 & 222 & 14 & 167,42 & 43,22 & 121 & 266 & 0,01 \\
\hline
\end{tabular}

\section{CONCLUSIONS}

Our results suggest of that in order to determining that baropodometry could be an effective tool to quantify postural control, highlighting an admissible and viable cost in the hospital approach of the patient after stroke in subacute phase.

\section{BIBLIOGRAPHY}

1. Thompson AJ. Neurological rehabilitation: from mechanisms to management. J Neurol Neurosurg Psychiatry 2000; 69: 718-22.

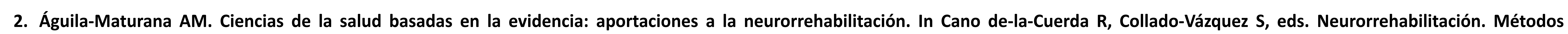
específicos de valoración y tratamiento. Madrid: Médica Panamericana; 2012. p. 51-9.

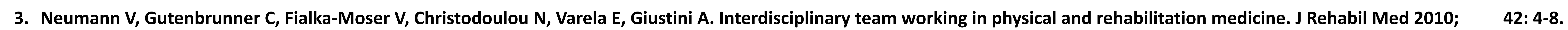

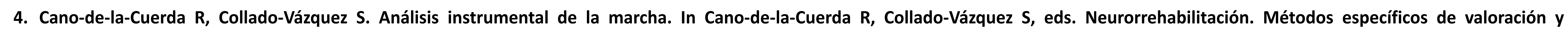
tratamiento. Madrid: Médica Panamericana; 2012. p. 161-70.

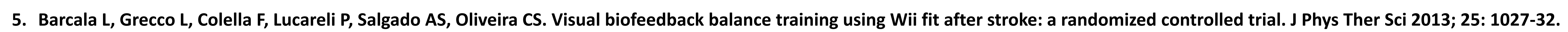

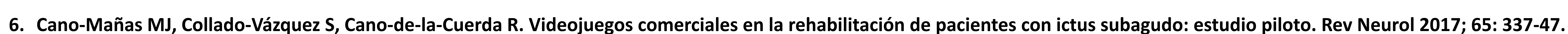

